\title{
Calibrating whole building energy model: a case study using BEMS data
}

\author{
E. Nolan \& J. Allsopp
}

Integrated Environmental Solutions Limited, Glasgow United Kingdom

A. Galata

Agenzia per l'Energia e lo Sviluppo Sostenibile, Modena, Italy

G. Pedone

Magyar Tudomanyos Akademia Szamitastechnikai es Automatizalasi Kutato Intezet, Budapest, Hungary

B. Zivkovic \& A. Sretenovic

University of Belgrade - Faculty of Mechanical Engineering, Belgrade, Serbia

ABSTRACT: This paper describes a Calibration methodology which is specifically configured to best match actual building performance, based on a case study conducted to calibrate whole building energy model using Building Energy Management System (BEMS) measured data. It details the calibration approach which was designed to meet the specific characteristic of the spaces, systems and energy use in the pilot school building. Two calibration methods were developed; one is for electrical and the other is for thermal energy along with calibrated weather file. The result shows excellent correlation with the measured electricity and room air temperature and demonstrates the effectiveness of the methodology. Mean Bias Error (MBE) and Cumulative Variation of Root Mean Squared Error (CVRMSE) for electricity consumption is $6 \%$ and $14 \%$ respectively and -5 and $7 \%$ for air temperature.

\section{INTRODUCTION}

The most accurate assessment of the impact of energy conservation measures (ECMs) normally requires a specifically configured and calibrated building energy simulation model. Building energy simulation model is often used in the building design phase and is primarily used for evaluating different building design choice. The assessment of these design choices can be made on baseline design. In this case, to ensure the most accurate assessment, it is essential to have the building simulation model to accurately predict the actual building performance.

This study is based on a case study school building which is called Lesa School to demonstrate a systematic, evidence-based calibration methodology for the whole building energy models using the IES Virtual Environmental Software. The study is part of the EC ICT_PSP-CIP VERYSchool project demonstration and validation activities, where the VERYSchool project will integrate smart LED lighting, smart metering, BEMS, energy simulation and energy action management software into a platform called the "Energy Action Navigator'" and demonstrate it in four pilot locations scattered in Europe.

This paper describes an evidence-based calibration of the energy simulation model for the whole pilot area of Lesa School Building.

\subsection{Case study: description of the calibrated build- ing}

The "A. Manzoni" elementary and Middle-grade school is located in Lesa (Novara, IT), Italy and was built in 1974. It is a two story building that during the year hosts an average of 180 people. The building has a total built area of $1,910 \mathrm{~m}^{2}$. The heating volume is about $11,160 \mathrm{~m}^{3}$. The building is heated by a single $423 \mathrm{~kW}$ capacity condensing boiler which also services domestic hot water. Solar thermal panels have been installed. The primary electrical load is lighting (standard fluorescent lamps) and some ventilation fans. There is no active cooling system and natural ventilation is used through windows. Typical electrical energy usage is $35 \mathrm{MWh} /$ year and natural gas usage is $40000 \mathrm{~m} /$ year which is equivalent to $383,790 \mathrm{MWh} /$ year. Energy use intensity is $34 \mathrm{MWh} / \mathrm{m}^{2}$, a typical value for a building of this size/use in the Northern Italy region.

For the VERYSchool project, a pilot area has been defined which encompasses nine classrooms, a common area, stairs, and three restrooms. Figure 1 show the pilot area within Lesa school building. The pilot has been instrumented with environmental and power sensors, and a building automation system.

\subsubsection{Site \& Geometry Model}

The baseline geometry model was created using architectural drawings. Room Height data were obtained from audited document. Web-based earth google image were used to confirm elevations and place glazing in approximately correction position. 


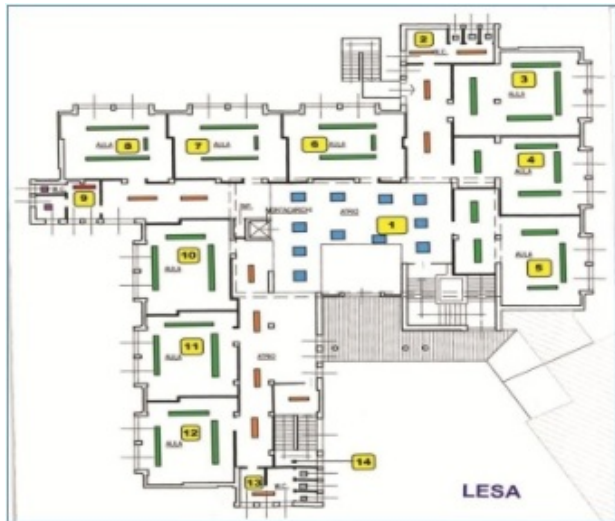

Figure 1. Lesa Pilot area

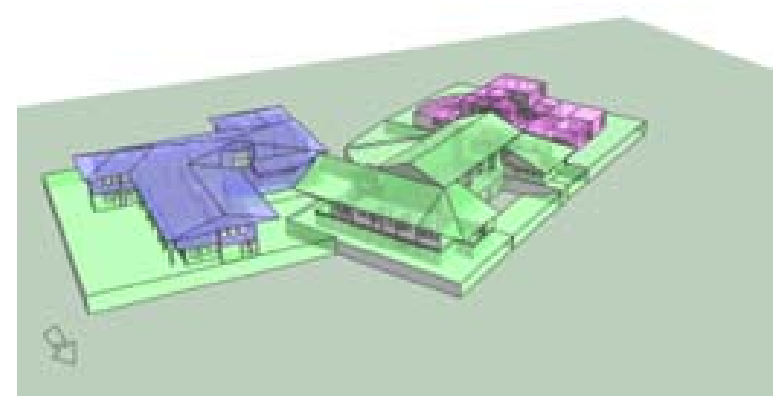

Figure 2. LESA School Site Model

\subsubsection{Construction}

Table 1 Characteristic of construction envelope

\begin{tabular}{ll}
\hline \multicolumn{1}{c}{ Envelope } & \multicolumn{1}{c}{ Characteristics } \\
\hline External Wall & $\mathrm{U}$-value $=1.9 \mathrm{~W} /\left(\mathrm{m}^{2 \circ} \mathrm{C}\right)$ \\
Internal Wall & $\mathrm{U}$-value $=1.19 \mathrm{~W} /\left(\mathrm{m}^{2 \circ} \mathrm{C}\right)$ \\
Roof & $\mathrm{U}$-value $=1.7 \mathrm{~W} /\left(\mathrm{m}^{2 \circ} \mathrm{C}\right)$ \\
Floor on the ground & $\mathrm{U}$-value $=1.05 \mathrm{~W} /\left(\mathrm{m}^{2 \circ} \mathrm{C}\right)$ \\
$\begin{array}{l}\text { Floor above the } \\
\text { ground }\end{array}$ & $\mathrm{U}$-value $=1.19 \mathrm{~W} /\left(\mathrm{m}^{2 \circ} \mathrm{C}\right)$ \\
$\begin{array}{l}\text { Door } \\
\text { External Window }\end{array}$ & $\mathrm{U}$-value $=2.5 \mathrm{~W} /\left(\mathrm{m}^{2 \circ} \mathrm{C}\right)$ \\
& $\mathrm{U}$-value $=2.5 \mathrm{~W} /\left(\mathrm{m}^{2 \circ} \mathrm{C}\right) ;$ \\
\hline
\end{tabular}

U-Value $=$ heat transfer coefficient SC: Shading coefficient

VLT: Visible light transmittance

\subsubsection{Internal Gains}

The VE building energy simulation program modelled the internal gains of occupancy, lighting, and plug loads obtained from audited document. Figure 3. shows the example of occupancy and lighting schedules;

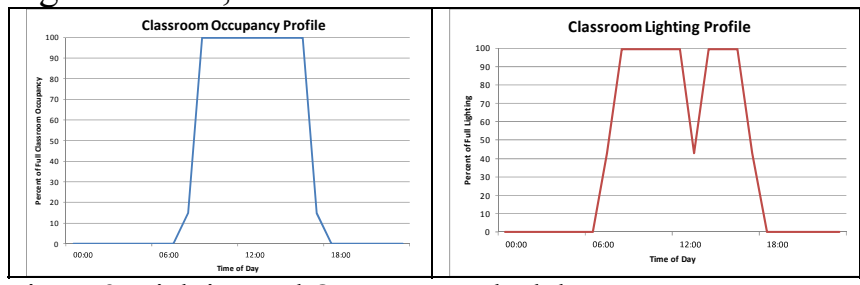

Figure 3. Lighting and Occupancy schedule

\subsubsection{HVAC systems}

The HVAC system is typically a primary energy usage system for a school building. In pilot area, heating system is a low-temperature hot water system for radiator supplied by a single boiler modelled with delivery efficiency of 0.94 and seasonal efficiency of 0.70 . Auxiliary energy was modelled with a value of $2.740 \mathrm{~W} / \mathrm{m}^{2}$.

\subsection{Installed Building Energy Management Sys- tem (BEMS)}

\subsubsection{Description of the BEMS}

Lesa School Building is equipped with advanced Building Energy Management System (BEMS) that provides minute-by-minute data on building operations. At the classroom level, this data includes temperature, lighting intensity, occupancy and heating system operational status. At the building level, this data includes energy consumption of electrical.

\subsubsection{Sensors and its data output}

Table 2 shows the list of selected sensor variables outputs taken from BEMS data collection for the calibration

Table.2 Selected BAS metered data variable output

\begin{tabular}{|l|c|}
\hline Sensor & Data Variable Output \\
\hline Temperature & ${ }^{\circ} \mathrm{C}$ \\
\hline Occupancy Presence & 1 or 0 \\
\hline Radiator & 1 or 0 \\
\hline Window & 1 or 0 \\
\hline Light Circuit Status & 1 or 0 \\
\hline Set-Point Room Temperature & ${ }^{\circ} \mathrm{C}$ \\
\hline
\end{tabular}

Hourly BEMS measured data was obtained for a targeted calibration period of two weeks because BEMS in Lesa School Building is not yet monitored for a full year.

\subsection{Weather data acquisition}

The VERYSchool project requires high quality archival data of a specific time period to calibrate the model, before an energy-saving prescription can be provided. The forecasted weather data for the next 24 hours are required to determine how the school's energy usage and environmental conditions will change according to the set optimisation scenario under ECM. There were three possible solutions in obtaining archival weather data;

- Install a dedicated weather station

- Use the results of a local weather station

- Interpolate the results of several local weather stations to find a more accurate result.

The quality of the data and the number of variable recorded from dedicated weather station can be 
less than at professional sites. The calibration data has already been obtained making impossible to measure this data. Result of a local weather station found at major airport the nearest to the Lesa School Building site, provides good quality continuous data but it has limitation as this site doesn't measure the solar radiation value.

The third option is to interpolate from existing weather stations, which is what a company called "Weather Analytics" using a grid based system. The altitude of weather station report is significantly higher $(585 \mathrm{~m})$ than the actual altitude of Lesa (230m).

Figure 4 shows the difference in temperatures between measured at the Lesa School Building and the Milan Malpensa weather station.

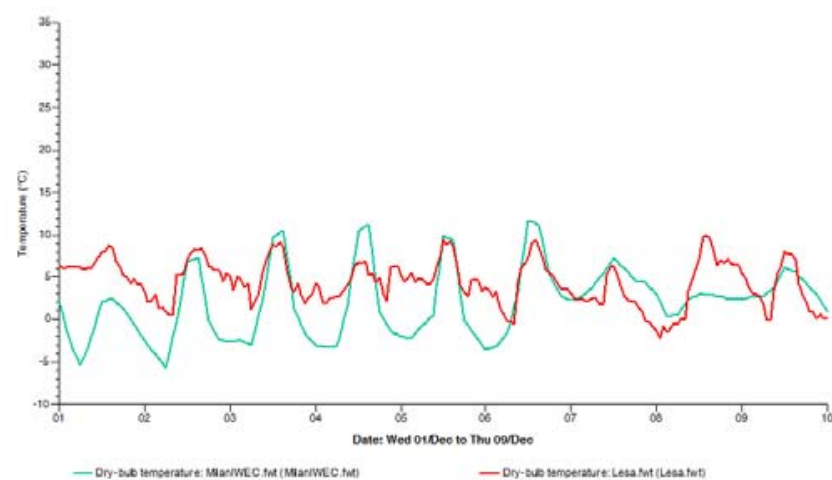

Figure 4. Difference in temperature between that measured at the Lesa School and the Milan Malpena weather station

It is not possible to determine the difference in temperature. This is due to the possible issue with the positioning of the sensor at Lesa School or a breakdown in the correlation between the two weather stations for this measurement. Figure 5 shows the evidence supporting the idea of correlation breakdown comes from between the two weather stations next to each other $5 \mathrm{~km}$, Milan Malpensa and NovaraCameri, which shows a discrepancy in temperature between the two EPW files.

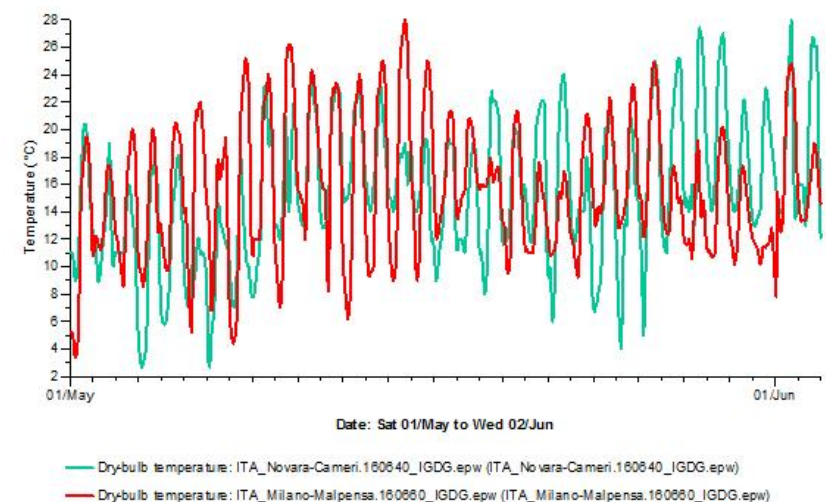

Figure 5. Comparison in temperature between two weather stations separated by $5 \mathrm{~km}$
It is possible that this discrepancy is due to the statistical construction of the EPW files, but if all the underlying variables are the same, the same output would be expected so the fact that files are different suggest that local difference are important even on $\mathrm{km}$ scale.

\subsubsection{Obtaining the data}

It has been decided to obtain both forecast and archive data from the "Weather Underground" website. This is done using a PHP script which produces CSV text files from the website which can then be loaded into IES's Excel-based weather file creator. FWT files are the file type primarily used by the IES $<$ VE $>$ simulation software for weather data. Two issues identified are that the website doesn't provide all of the variables required for the FWT file and that the forecasts are done on a three hour time step. The variables missing are the solar irradiances for both and the cloud cover for the archive data.

IES have developed a strategy for dealing with these issues. The cloud cover data for the forecast will be used to build up the archive data, and the forecast data will be interpolated. The solar irradiance is estimated from other measured values.

Following the solar radiation flux at the top of the atmosphere is a known constant $\left(1360 \mathrm{~W} / \mathrm{m}^{2}\right)$, the elevation of the Sun is known for a given location on the Earth's surface and time, so using the relative humidity as a measure of the attenuation of the Sun's radiation allows an estimate for the solar radiation value to be calculated. This is described in more detail below;

The total incident solar radiation $\left(\mathrm{G}_{\mathrm{th}}\right)$ is the summation of two components, the direct beam radiation $\left(\mathrm{G}_{\mathrm{Bh}}\right)$ and diffuse solar radiation $\left(\mathrm{G}_{\mathrm{Dh}}\right)$

$$
\begin{aligned}
& G_{t h}=G_{B h}+G_{D h} \\
& G_{B h}=G_{P h} \cos \left(\theta_{z}\right)
\end{aligned}
$$

$\mathrm{GPh}$ is the beam radiation received on a perpendicular surface to the incoming radiation. Goh is the solar radiation flux $(1.360 \mathrm{~kW} / \mathrm{m} 2)$ at the top of the atmosphere, $\tau$ is the atmospheric transmittance and $\mathrm{m}$ is the optical air mass number. $\tau$ is a value which steps between 0.2 (very cloudy) and 0.69 (very transparent sky) in response to changes in the relative humidity.

$$
G_{P h}=G_{o h} \tau^{m}
$$

$\mathrm{M}$ is calculated as below, where 101.3 is the air pressure at sea level $(\mathrm{kPa})$

$$
m=\frac{P_{a}}{\left(101.3 \cos \left(\theta_{z}\right)\right)}
$$

$\mathrm{Pa}$ adjusts for the altitude of the site, in metres above sea level. 


$$
P a=101.3 e^{-(a / 8200)}
$$

This relationship provides a value for the diffuse radiation, [6]:

$$
G_{D h}=0.3\left(1-\tau^{m}\right) G_{o h} \cos \left(\theta_{z}\right)
$$

To match the data to the EPW file's Global Horizontal irradiance, the following formula was used:

For the 2005 EPW file for Milan Malpensa Airport, $G H R_{E P W}$ was compared to $G_{B h}+G_{D h}$, using the time values and the relative humidity, with the resultant plot being shown below. The weather data are arranged by World Meteorological Organization region and Country.

This was checked for correlation and has a correlation co-efficient of about 0.94 . Therefore this technique will be used to determine the Global Horizontal radiation value for the weather file.

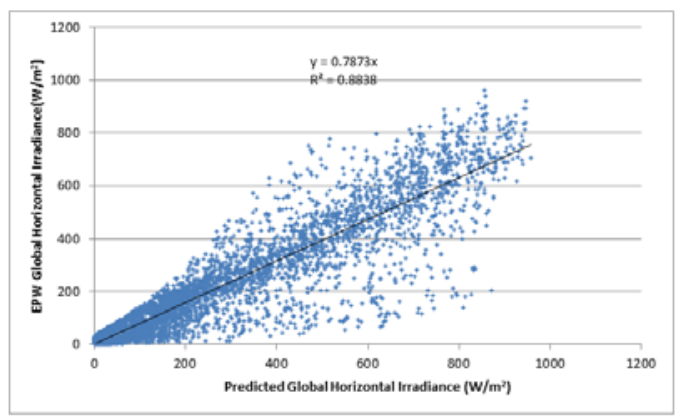

Figure 6. Global Horizontal Radiation Comparison

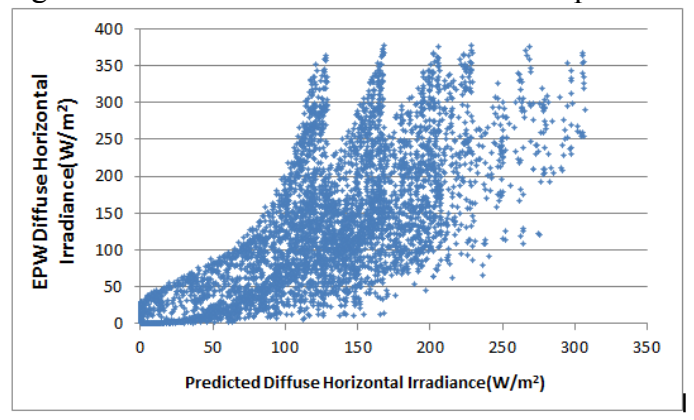

Figure 7. Global Diffuse Radiation Comparison

Figure 6 shows the diffuse radiation where EPW values were significantly greatly than those calculated using the above method but there is still strongly correlated, with a co-efficient of 0.86 . From these two irradiance measures, all of the measures in the FWT file can be calculated.

\subsection{CALIBRATION}

\subsection{Calibration approach}

The calibration approach for the pilot area has been designed to meet the specific characteristics of the spaces, systems, and energy use data available in Lesa pilot area. The pilot area has no forced ventilation systems, therefore electrical and thermal en- ergy usage can be nominally separated. For electrical energy use, the primary load is the classroom lighting and electrical energy use data is available for the pilot area from the installed BEMS. For thermal energy, the primary load is the hot water radiators for heating and thermal energy use data was only available on a monthly basis for the whole building. Given this configuration, two calibration methods were performed: one method for electrical energy, one method for thermal energy.

For electrical energy usage, a calibration period was selected with no heating load. In addition, since the pilot area was specifically instrumented for electrical energy use, these measured energy values could be directly used in the calibration process.

For thermal energy, only whole-building natural gas usage data was available for a monthly time period. While calibration can be performed using IPMVP metrics for this situation, for the specific purposes of the VERYSchool project the quality of the calibration is not ideal. This is not a desirable outcome given that the school uses much greater levels of thermal energy than electrical energy.

Therefore it is decided to augment a nominal monthly, whole-building thermal energy calibration with a classroom-level calibration. Two calibration methods were performed on the following basic steps of the calibration process;

- The building geometry is developed using available audited information from architectural drawings, building site survey and document

- The building energy system model is developed from mechanical system drawings/building site surveys.

- BEMS data is obtained for a targeted calibration period 1-2 weeks. Localised calibrated weather data is obtained for the target period

- The building energy simulation model is run and results compared to BEMS data.

- An iterative process is performed identifying sources of discrepancy between the BEMS data and the building simulation model. Typical sources of discrepancy include: inaccurate building envelope data, inaccurate heating/system, lighting loads, occupancy, plug loads, etc. Each potential source of discrepancy is investigated and adjusted as necessary to achieve the desired match between BEMS data and building simulation results.

- An iterative process is in repeated for other time periods to account for seasonal specific conditions and apply IPMVP metric calculation on simulated result. 


\subsection{Calculation of calibration metrics}

It is necessary to define an acceptable error margin in comparison to monitoring data via calibration of building energy simulation mode. To determine the "goodness" of the calibration technique the following IPMVP calibration metrics was applied;

Normalised Mean Bias Error ( $M B E$ );

$$
M B E=\frac{\Sigma\left(S_{i}-M_{i}\right)}{\Sigma M}
$$

Coefficient of Variation ( $C V$ );

$$
\begin{aligned}
& C V=\frac{R M S E}{\bar{M}} \\
& R M S E=\sqrt{\frac{\sum\left(S_{i}-M_{i}\right)^{2}}{n}}
\end{aligned}
$$

Coefficient of Determination $\left(\mathbb{R}^{2}\right)$;

$$
R^{2}=\left[\frac{\Sigma\left(M_{i}-\bar{M}\right)\left(S_{i}-\bar{S}\right)}{\sqrt{\Sigma\left(M_{i}-\bar{M}\right)\left(S_{i}-\bar{S}\right)^{2}}}\right]^{2}
$$

Based on BEMS data provides minute-by-minute data, IPMVP provides guidance as to targets for $\mathrm{CV}$, $\mathrm{MBE}$ and $\mathrm{R}_{\text {target }}^{2}$ for hourly based calibration is selected and the targets are;

$$
\begin{gathered}
C V \# 30 \% \\
M B E= \pm 10 \% \\
\mathrm{R}_{\text {target }}^{2} \geq 60 \%
\end{gathered}
$$

\subsection{Weather effect on calibration}

For typical building design tasks, statistical regional weather files are sufficient to evaluate basic building design alternatives. However, for the enhanced energy efficiency goals of the VERYSchool project, a higher level of accuracy is require, IES developed a process to obtain both date-accurate regional and local weather. Regional weather was obtained from the Milan Malpensa airport and local weather was obtained using Lesa BEMS measured data augmented by the methods developed in Section 1.3.1.

\subsection{RESULT AND DISCUSSION}

\subsection{Electrical energy calibration}

Figure 8 shows total measured and simulation model electrical power for the pilot area in one week period $24^{\text {th }}$ September to $7^{\text {th }}$ October.

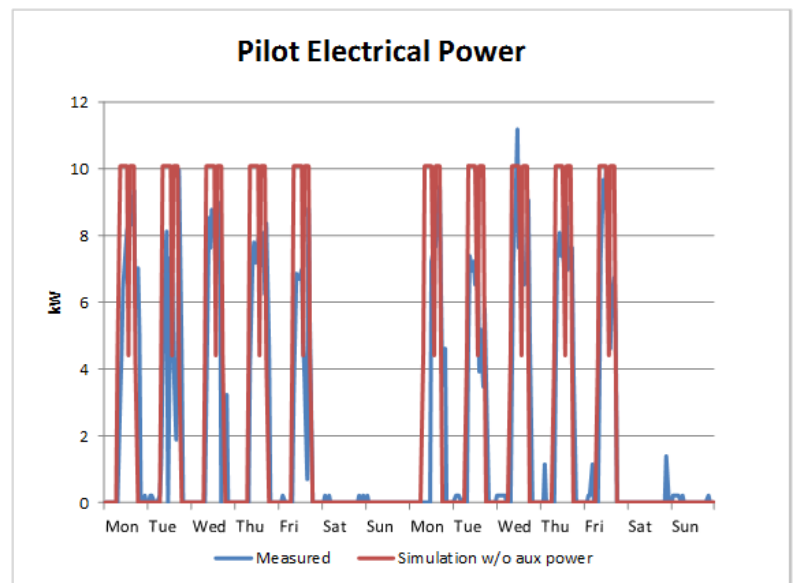

Figure 8. Pilot electrical power

The analysis of the simulation results showed that the simple HVAC heating modelled auxiliary power e.g. distribution pumps to the overall electrical consumption. The heating system was turned off during period and would be using no auxiliary power and the pilot electrical metering is not capturing this heating system auxiliary energy.

Figure 9 shows the electrical power between measured and simulation after heating system is modelled without auxiliary power.

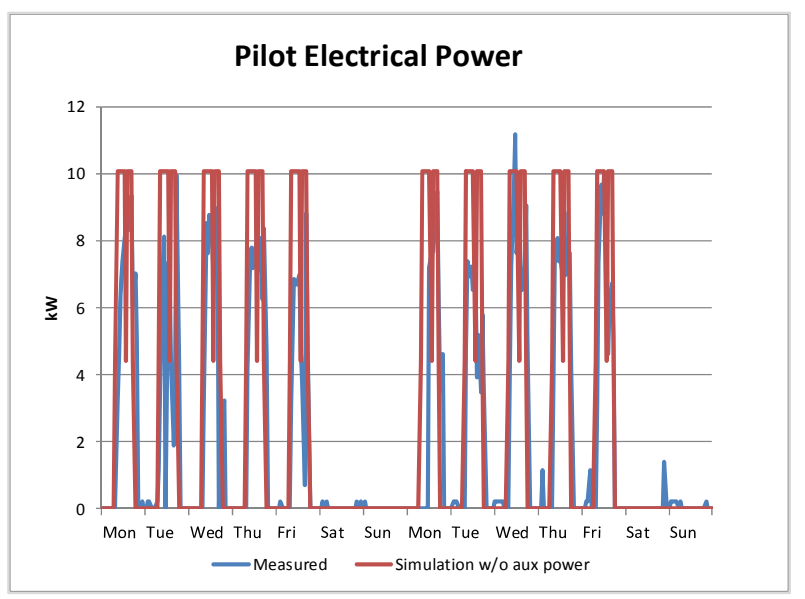

Figure 9. Initial Testing w/o Heating System Auxiliary Energy

The simulated electrical usage is dictated directly by the input lighting profile taken from audited. The use of direct measured lighting identified model inaccuracies in lighting system specification and operations. Figure 10 shows simulated and actual results when the model was 'driven' by the actual lighting measurement from the BEMS. 


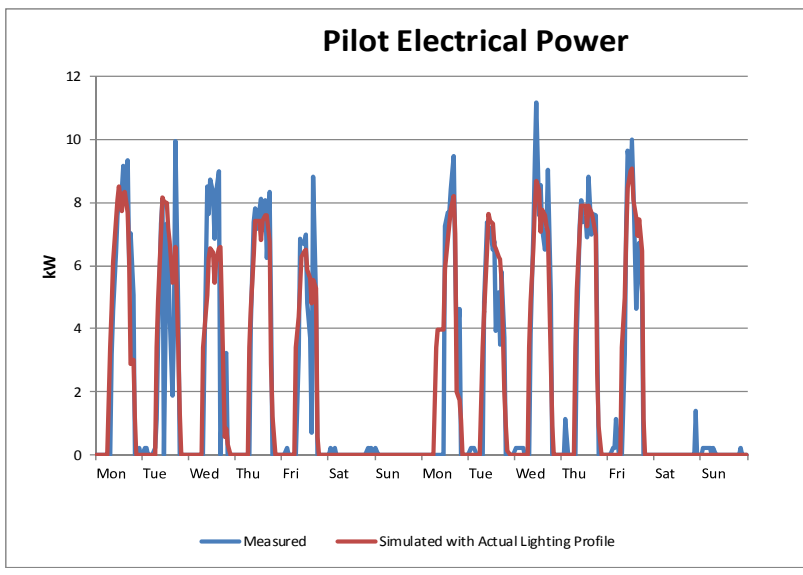

Figure 10. Measured and Survey Lighting Profile

Table 3 shows the results of the IPMVP calibration metrics were met for electrical energy calibration.

Table 3 Electrical Energy Calibration Summary

\begin{tabular}{|c|l|c|c|c|}
\hline Sim run no. & \multicolumn{1}{|c|}{ Adjustment } & CV & MBE & R2 \\
\hline \multicolumn{5}{|c|}{ Electricity Energy IPMVP Hourly Calibration Tuning } \\
\hline $\mathbf{1}$ & Baseline - simple HVAC modelling & $141 \%$ & $69 \%$ & $64 \%$ \\
\hline $\mathbf{2}$ & $\begin{array}{l}\text { Remove simple HVAC heating auxil- } \\
\text { iary energy }\end{array}$ & $128 \%$ & $35 \%$ & $64 \%$ \\
\hline $\mathbf{3}$ & $\begin{array}{l}\text { Detailed HVAC modelling w/actual } \\
\text { lighting profile }\end{array}$ & $\mathbf{1 4} \%$ & $\mathbf{6 \%}$ & $\mathbf{9 7 \%}$ \\
\hline
\end{tabular}

MBE and CVRMSE for electricity consumption is $6 \%$ and $14 \%$ respectively for the final modelling with detailed lighting profile using metered data. This result is interpreted as strong consistency of the simulation model with monitoring data, for lighting profile.

\subsection{Thermal energy calibration}

As indicated prior, a surrogate method is to choose to calibrate the thermal energy modelling by comparing measured individual classroom temperatures with simulated results. Figure 11 shows an initial plot of classroom temperatures for the baseline model without calibration. Both steady-state and dynamic bias are evident from classroom air temperature graph figure.

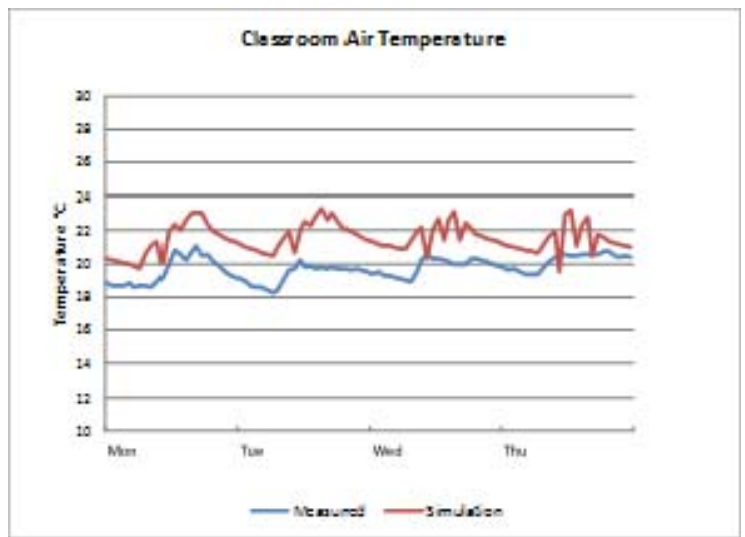

Figure 11. Classroom 5 air temperature, measured vs simulated
The dynamic error may indicate that heat inputs to the classroom need adjustment, the classroom-level calibration is performed using the BEMS measured radiator on/off values to simulate same heat input profile as the actual room to compute a thermalbalance on the classroom. Figure 12 continues to show both steady-state and dynamic bias.

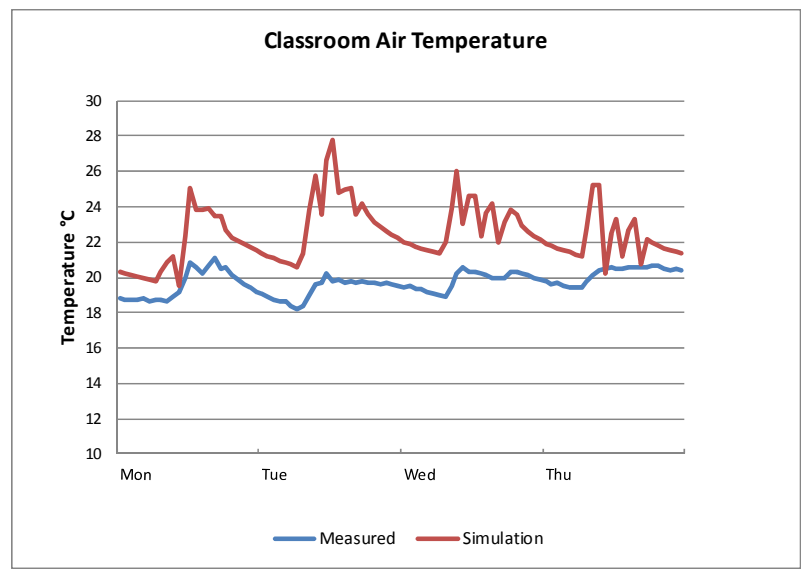

Figure 12. Thermal Calibration - Actual Radiator On/Off Profile

Figure 13 shows the temperature swings are reduced after radiator heating output capacities is adjusted from initial estimates. The significant steady-state errors remain same.

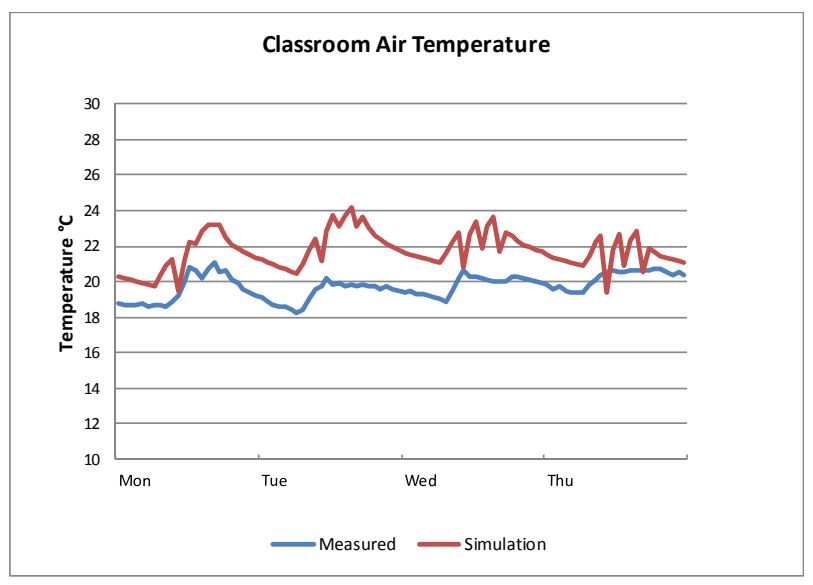

Figure 13. Thermal Calibration - Adjusted Radiator Capacity

Occupancy is modelled as a fixed for the simulation as this difference between the fixed schedule and actual occupancy can be large source of model error. Figure 14 shows more accurately modelling classroom occupancy with classroom occupancy schedule adjusted using a combination of the measured presence detection sensor and class size. 


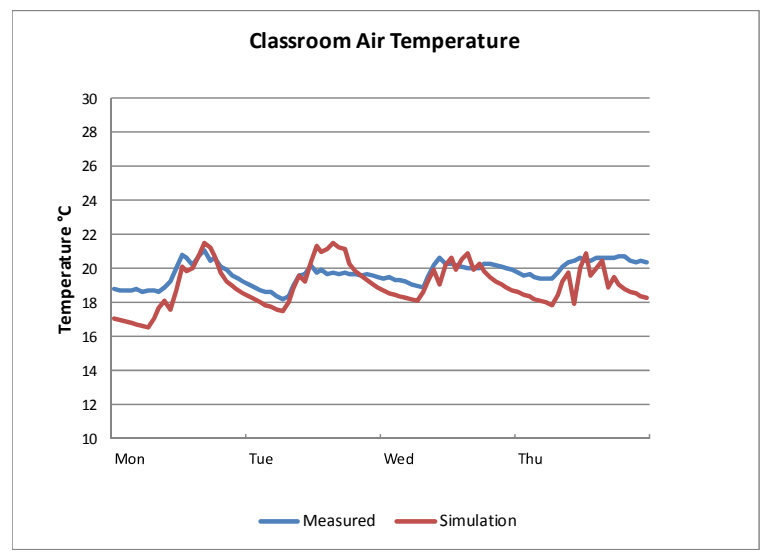

Figure 14. Thermal Calibration -"Measured" Occupancy Schedule

Figure 14 shows a good steady state calibration match, possible potential source of calibration error could be impacting the temperature dynamic of model driven by the room thermal envelope properties. Figure 15 shows the simulation result after classroom thermal envelope was adjusted with the heavier wall construction

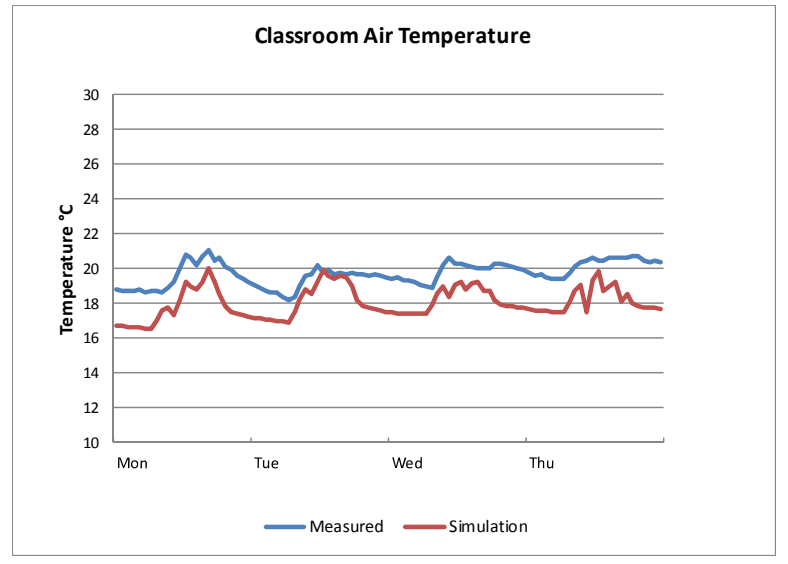

Figure 15. Thermal Calibration Step 4- Heavy Wall Construction

Thermal dynamics have been dampened but steadystate simulation values are below measured implies the heavier thermal mass is acting as cool heat sink. Modelled occupancy schedule simulation from Fig. 14 best captures the selected classroom temperature dynamics.

Table 4 shows the results of the IPMVP calibration metrics were met for Aula 5 space (Classroom 5) thermal energy calibration.

Table 4 Classroom 5 Thermal Energy Calibration Summary

\begin{tabular}{|c|l|c|c|c|}
\hline Sim run no. & \multicolumn{1}{|c|}{ Adjustment } & CV & MBE & R2 \\
\hline \multicolumn{5}{|c|}{ Thermal Energy IPMVP Hourly Calibration Tuning } \\
\hline $\mathbf{1}$ & Baseline & $9 \%$ & $8 \%$ & $18 \%$ \\
\hline $\mathbf{2}$ & Measured radiator profile from BEMS & $14 \%$ & $12 \%$ & $11 \%$ \\
\hline $\mathbf{3}$ & Adjusted radiator capacities & $10 \%$ & $9 \%$ & $11 \%$ \\
\hline $\mathbf{4}$ & $\begin{array}{l}\text { Measured occupancy profile from } \\
\text { BEMS }\end{array}$ & $7 \%$ & $-5 \%$ & $26 \%$ \\
\hline $\mathbf{5}$ & $\begin{array}{l}\text { Adjusted constructions (light to } \\
\text { heavy) }\end{array}$ & $10 \%$ & $-9 \%$ & $38 \%$ \\
\hline $\mathbf{6}$ & Increased radiator capacities & $9 \%$ & $-8 \%$ & $34 \%$ \\
\hline
\end{tabular}

MBE and CVRMSE for thermal consumption (air temperature) is $-5 \%$ and $7 \%$ respectively for final initial modelling using metered data and are within in acceptable range of error margin.

\subsection{Pilot Area Thermal energy calibration}

Based on thermal surrogate method and using tidier measured data for January period allows to expand the thermal calibration on whole pilot area in model to examine the further comparison between measured and simulation result during January period. The tidier BEMS data were obtained to allow the simulation model with lighting usage, occupancy schedule, radiator usage and window opening usage. Figure 16 shows large steady state temperature bias and the simulated temperature are much lowered than measured.

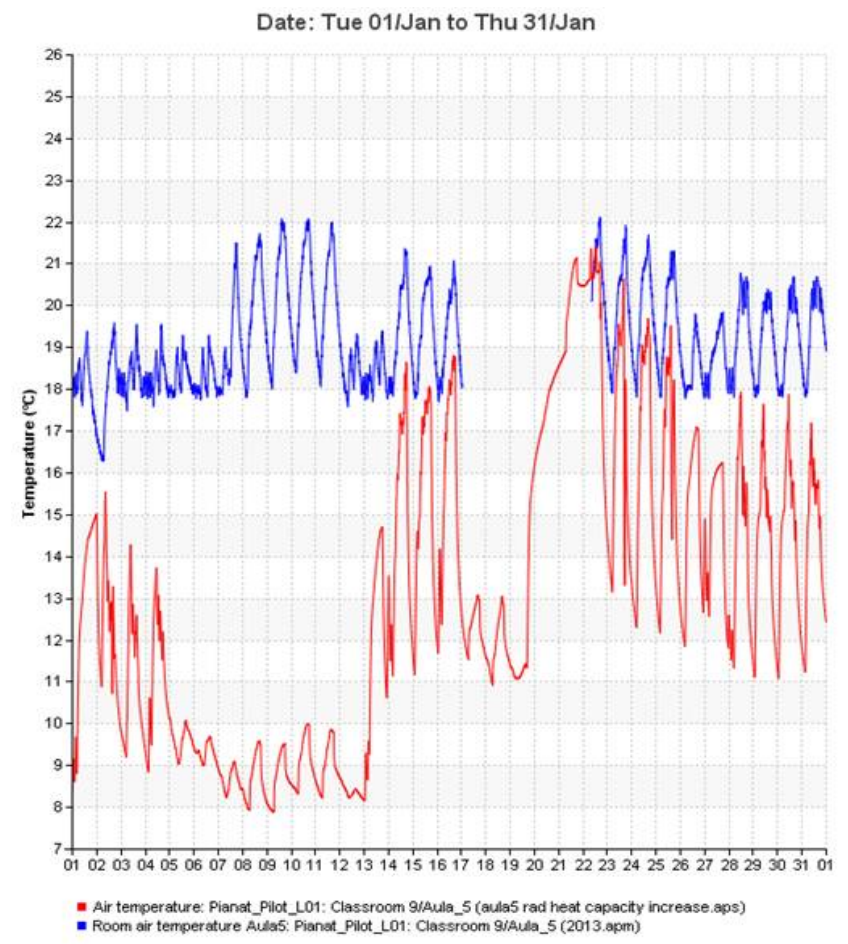

Figure 16. Thermal calibration- All metered data assigned

Window opening metered data is binary and doesn't record the amount of window opening area assuming all windows are open at same time. Figure 17 shows the drop in room air temperature in adjacent spaces to Aula 5 cause by window opening in adjacent spaces thus reducing room air temperature caused by internal conduction heat losses transfer to adjacent space. 


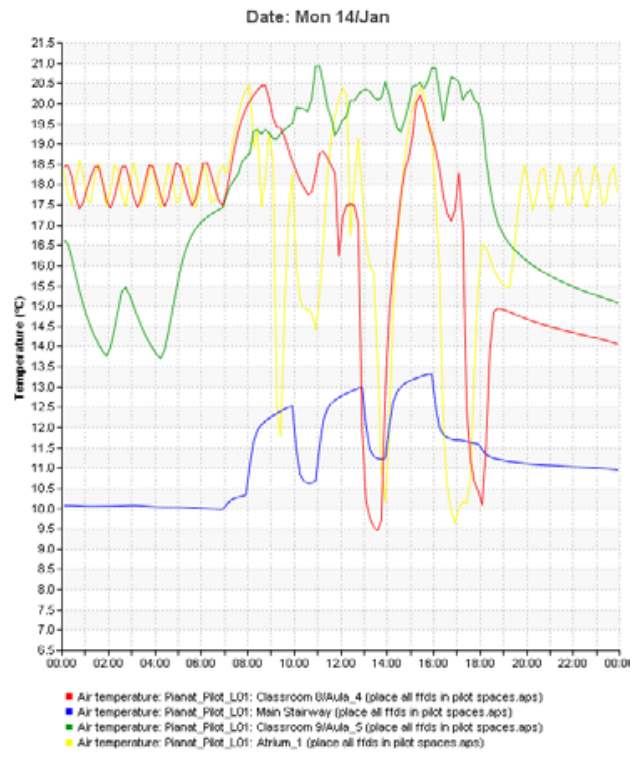

Figure 17. Thermal Calibration step 5: Room temperature difference between Aula 5 and adjacent spaces

It is identified the window opening should be able separate outs its effect from other things that could be possibly mis-calibrated, which it is led to believe that the window 'error' could be masking other calibration errors which it has been addressed.

The following steps of calibration process to eliminate the dynamic air temperature swings in all pilot classroom spaces in pilot area;

- Close all windows

- Assigned all radiators in pilot area with BEMS metered data

- Eliminate the adjacent space with window opening to stop large internal conduction loss from pilot space

- Each pilot space's radiator heat output capacity is adjusted to bring simulated room temperature closer to measured air temperature.

The results of the IPMVP calibration metrics on room temperature comparison are summarized in following table 5. Based upon this analysis, it is evident that modified window schedule, infiltration, layers simulation model best captures the selected classroom temperature dyanmics.

Table 5 Pilot Thermal Energy calculation

\begin{tabular}{|c|c|c|c|}
\hline \multicolumn{4}{|c|}{ Thermal Energy IPMVP Hourly Calibration Tuning } \\
\hline Room & MBE & CV & $\mathbf{R}^{2}$ \\
\hline Aula3 & $-6 \%$ & $8 \%$ & $70 \%$ \\
\hline Aula4 & $-12 \%$ & $13 \%$ & $76 \%$ \\
\hline Aula5 & $-8 \%$ & $12 \%$ & $63 \%$ \\
\hline Aula6 & $-1 \%$ & $4 \%$ & $80 \%$ \\
\hline Aula7 & $0 \%$ & $4 \%$ & $37 \%$ \\
\hline Aula 8 & $3 \%$ & $6 \%$ & $60 \%$ \\
\hline Aula10 & $-1 \%$ & $5 \%$ & $59 \%$ \\
\hline Aula11 & $-2 \%$ & $3 \%$ & $34 \%$ \\
\hline Aula12 & $0 \%$ & $5 \%$ & $28 \%$ \\
\hline
\end{tabular}

MBE and CVRMSE results for all classroom temperature are within in acceptable range of error mar- gin indicate the strong consistency of the simulation model with monitoring data.

\subsection{CONCLUSIONS}

Electrical and thermal energy calibration of the Lesa School Building energy simulation model was performed where the calibrations resulted in significant changes to the simulation model that results in higher accuracy in predicting building performance. IPMVP calculation metrics were met for both the electrical and thermal energy calibrations. This will be a key element in the VERYSchool Energy Navigator's ability to recommend and predict the effective school energy management procedures.

BEMS data was not access directly by IES developed tool, there was intermediary steps in obtaining and tidied up raw data however it was identified there should be scalable data structure to allow IES to access metered data quick which results in recently developed a new toolkit called 'IES SCAN' to facilities the data transfer in effective way.

It has been determined that such simple building like Lesa school building where the dimensionality of iterative calibration process tend get very large and quick, it is difficult to find final solution on itself as the process sometimes leads to non-sense change therefore it is agreed the need of more power tools to reduce complexity problem.

\subsection{ACKNOWLEDGEMENT}

The VERYSchool project (GA n ${ }^{\circ} 297313$ for CIPPilot actions) received funds by the EC under the ICT-PSP-CIP framework Program. The Consortium is made by 12 Partners, which collectively contribute to achieve the project results.

\subsection{REFERENCE}

Gucyeter Basak \& Gunaydin H.Murat, Optimisation of an envelope retro strategy for an existing office building.

Firmanda Dimas, Riza Al, IhtshamulHaqGilani Syed \& Shiraz Aris Mohd. 2011. International Journal of Environmental Science and Development vol. 2, no. 3, pp. 188-193.

Firmanda Dimas \& Riza Al. Hourly Solar Radiation Estimation Using Ambient Temperature and Relative Humidity Data, Table 1.

D5.1 Energy Audits results Annex A - LESA Pilot

EnergyPlus Weather file format,

http://apps1.eere.energy.gov/buildings/energyplus/weatherd ata about.cfm.

Campbell G. S. \& Norman J. M. 1998. Introduction to Environmental Biophysics. 2nd ed. New York: Springer-Verlag 167-183.

International Performance Measurement and Verification Protocol (IPMVP) volume I 2002.

Weather Underground, http://www.wunderground.com. 